NASA Technical Memorandum 88913

AIAA-87-0525

\title{
High-Speed Propeller Noise Predictions: Effects of Boundary Conditions Used in Blade Loading Calculations
}

M. Nallasamy

Sverdrup Technology, Inc.

Lewis Research Center

Cleveland, Ohio

and

B.J. Clark and J.F. Groeneweg

Lewis Research Center

Cleveland, Ohio

Prepared for the

25th Aerospace Sciences Meeting

sponsored by the American Institute of Aeronautics and Astronautics

Reno, Nevada, January 12-15, 1987 


\author{
M. Nallas amy \\ Sverdrup Technology, Inc. \\ Lewis Research Center \\ Cleveland, Ohio 44135 \\ and \\ B.J. Clark and J.F. Groeneweg \\ National Aeronautics and Space Administration \\ Lewis Research Center \\ Cleveland, Ohio 44135
}

\section{Abstract}

The acoustics of an advanced single rotation SR-3 propeller at cruise conditions are studied employing a time-domain approach. The study evaluates the acoustic significance of the differences in blade pressures computed using nonreflecting rather than hard wall boundary conditions in the three-dimensional Euler code solution. The directivities of the harmonics of the blade passing frequency tone and the effects of chordwise loading on tone directivity are examined. The results show that the maximum difference in the computed sound pressure levels due to the use of blade pressure distributions obtained with the nonreflecting rather than the hard wall boundary conditions is about $1.5 \mathrm{~dB}$. The blade passing frequency tone directivity obtained in the present study shows good agreement with Jetstar flight data.

\section{Introduction}

Advanced high speed propellers incorporate many features which are quite different from those of conventional low speed propellers. Advanced propeliers employ eight or ten highly loaded, low aspect ratio, thin and highly swept blades. These high speed propellers with transonic helical tip Mach numbers produce significantly more noise than low speed propellers. Therefore, special attention must be paid to reducing high speed propeller noise. To accomplish this, an understanding of the noise generation and radiation mechanisms and noise control techniques is essential. Analytical models, numerical approaches and experimental methods are being developed to understand and predict highspeed propeller noise levels. 1-4

Propeller noise consists of two dominant components: (1) Thickness noise and (2) loading noise. The thickness noise component is governed by the geometry of the blade and can be computed reasonably accurately. The loading noise component depends on the blade pressure distribution, which has of ten been estimated by approximate methods for input to the acoustic computations. With the availablilty of super-computers the blade pressure distribution can be obtained more accurately by solving the full three-dimensional Euler equations governing the flow field of a high speed propeller.

The blade pressure distributions obtained from the Euler analysis of the propeller flow field can be employed to compute the sound pressure levels of advanced propeller tones by $a_{5}$ procedure such as that used by Clark and Scott. ${ }^{5}$ They modified the
Denton code ${ }^{6}$ developed for the three-dimensional analysis of the flow in turbomachines to compute the propeller flow field. Their modification consisted of moving the casing away from the blade tip to a distance of twice the blade radius from the axis of the propeller. In other words, the flow field of the propeller, which is unconfined, was modeled as though the propeller was inside a much larger solid-walled duct. It has been arqued that the hard wall boundary condition could significantly affect the computed blade pressure distributions, and the noise levels computed from these pressure distributions could be significantly in error.

The present investigation was undertaken to establish the influence of the far field boundary condition on the blade pressure distribution and on the noise levels computed from them. The hard wall boundary condition is replaced by a nonreflecting boundary condition. The characteristic variable corresponding to the incoming acoustic information is imposed on the boundary. The blade pressure distributions obtained with this boundary condition are compared with those obtained with the hard wall boundary condition. The acoustic significance of the change in blade pressure distributions due to the implementation of the nonreflecting boundary conditions is evaluated. This is done by computing blade passing tone directivities using the blade pressure distributions obtained with the two boundary conditions as input to Farassat's computer program for sound pressure levels. The computed directivities are compared with flight data obtained on the SR-3 model propeller installed on the Jetstar test bed aircraft as shown in Fiq. 1 . The computed directivities of the higher harmonics of the blade passing frequency and the effect of chordwise loading on directivity are also examined.

\section{Computation of Blade Pressure Distributions}

In the present study we consider the acoustics of the SR-3 high-speed propeller at design conditions. The blade pressure distributions are obtained by solving the three-dimensional Euler equations employing Denton's time marching method. As mentioned above, the hard wall boundary condition of Ref. 5 for the outer boundary of the computational domain representing the propeller flow field is replaced by a nonreflecting boundary condition. The specification of the nonreflecting boundary condition reduces the influence of the location of the far field boundary on the solution. Further details of the nonreflecting boundary condition employed, the aerodynamic solutions 
obtained, and the comparison of the solutions with data and other predictions are reported in Ref. 8 . The blade pressure distributions obtained for the SR-3 propeller blade at design conditions (advance ratio of 3.06 and a flight Mach number of 0.8 ) are shown in Fig. 2. Pressure distributions on the blade are shown at 21,53 , and 84 percent span. First, it is seen that significant differences exist between the pressure distributions obtained with the hard wall and the nonreflecting boundary conditions. The higher pressures with the hard wall boundary condition are attributed to the pressure rise due to the confining wall. It is also shown in Ref. 8 that the results obtained with the nonreflecting boundary condition are in better agreement with the experimental data than those obtained with a hard wall boundary condition. The computed total power coefficient, elemental power coefficient, elemental thrust coefficient and the flow swirl angle downstream of the blade were compared with the experimental data.

Figure 3 shows chordwise loading distributions in terms of normalized differential pressure $\Delta C_{p}$ at seven spanwise locations, namely $16,26,37,53$, 63,79 , and 95 percent span. With the nonreflecting boundary condition, the pressure difference near the leading edge is reduced and the peak near the trailing edge is sharpened compared to that for the hard wall boundary condition. This chordwise loading distribution influences the directivity of the blade passing frequency tone as discussed in the Results section. The peak in the loading distribution near the trailing edge is due to the trailing edge shock system observed in the aerodynamic analysis and experiments. 1 It is instructive to note here that the approximate methods used to calculate the loading distribution, such as that of Hanson 9 (see Fig. 14 of Ref. 9), show little evidence of a trailing edge shock system. The radial distributions of the loading for the two boundary conditions are shown in Fig. 4. The hard wall boundary condition results in a higher loading than the nonreflecting boundary condition. The power coefficient calculated with the hard wall boundary condition is about 11 percent higher than the measured value at design conditions, while that obtained with the nonreflecting boundary condition is about 3 percent lower than the measured value.

\section{Computation of Advanced Propeller Noise}

The blade pressure distributions obtained above are used as input to the acoustic computation employing Farassat's code.7,10 This computer code for advanced propeller noise prediction uses a time domain formulation. It is valid for both near and far field noise calculations and handles observers fixed to the ground frame or fixed to the aircraft frame. His formulation uses two forms of the solution of the Ffowcs-Williams and Hawking equation with thickness and loading source terms only.

The governing equation of the acoustic pressure $p^{\prime}(x, t)$ of a propeller ${ }^{7}$ is

$$
\begin{aligned}
\frac{1}{c^{2}} \frac{\partial^{2} p^{\prime}}{\partial t^{2}}-\nabla^{2} p^{\prime}=\frac{\partial}{\partial t}\left[\rho_{0} v_{n}\left|\nabla_{f}\right| \delta(f)\right] & -\frac{\partial}{\partial x_{i}}\left[1_{i}|\nabla f| \delta(f)\right]
\end{aligned}
$$

where $c$ and ${ }_{0}$ are the speed of sound and density in the undisturbed medium respectively, and $V_{n}$ is the local normal velocity on the blade surface, which is described by the equation $f(x, t)=0$. The local force (per unit area) on the fluid by the blade surface is $l_{i}$, and $\delta(f)$ is the Dirac delta function. The following two forms of the solution of Eq. (1) are used to calculate propeller noise in Farassat's code:

$$
\begin{aligned}
4 \pi p^{\prime}(\bar{x}, t)= & \frac{1}{C} \frac{\partial}{\partial t} \int_{f=0}\left[\frac{\rho_{0} C v_{n}+l_{r}}{r\left|1-M_{r}\right|}\right]_{r e t} d s \\
& +\int_{f=0}\left[\frac{1_{r}}{r^{2}\left|1-M_{r}\right|}\right]_{r e t} d s \quad \text { (subsonic) } \\
4 \pi p^{\prime}(\bar{x}, t)= & \frac{\partial}{\partial t} \int_{f=0} \frac{\rho_{0} C v_{n}+1_{r}}{r \sin \theta} d r d \tau \\
& +\int_{f=0} \frac{C 1_{r} d \tau d \tau \text { (transonic) }}{r^{2} \sin \theta} d=0
\end{aligned}
$$

where ds is an element of surface area of the blade $f=0$ and $d r$ is an element of length of the curve of intersection for the surface $f=0$ and the radiation vector $\bar{r}=\bar{x}-\bar{y}$. Suffix $r$ refers to the radiation direction. $M_{r}=\bar{v} \cdot \overline{\hat{r}} / c$, where $\bar{v}$ is the local velocity on the blade surface and $\overline{\hat{r}}$ is the unit vector in the radiation direction. $\theta$ is the angle between the surface normal and the radiation vector, $g=\tau-t+r / c=0$ is the equation of the collapsing sphere centered at the observer position $x, t$ is the observer time, and $\tau$ is the source time. Equation (2) is used for $M_{r}<0.98$ and Eq. (3) is used for $M_{r}>0.98$. The equations are solved numerically using finite difference techniques.

The upper and lower surfaces of the blade are divided into panels. The computed pressure distribution (from the aerodynamic code) on these panels is used to calculate the acoustic pressure signature at any observer position. The contributions of all panels are added together to obtain the acoustic pressure $p^{\prime}(\bar{x}, t)$. The pressure signature for only one blade is computed. The signature for several blades is calculated by shifting the signature for one blade in time and summing the pressures for each observer time with in a period. The acoustic pressure signature is then Fourier analyzed to obtain the spectrum of noise.

\section{Discussion of Results}

The computations have been carried out for the eight bladed SR-3 model propeller configuration for the design conditions - flight Mach number of 0.8 , flight altitude of $35000 \mathrm{ft}$ and an advance ratio of 3.06. The detailed pressure distributions on the blade surfaces obtained from the aerodynamic calculations are used as input to the acoustic computations. The results of the computations and comparisons with the Jetstar flight datall are 
presented and discussed. The microphone positions in the flight test are shown in Fig. 5 to aid discussion of the results.

\section{Boundary Condition Effects}

First we examine the effect of the far field boundary condition employed in the aerodynamic calculations on the acoustic results. The blade pressure distributions obtained with the hard wall boundary condition and the nonreflecting boundary condition at the outer boundary of the computational domain for aerodynamic calculations are used to calculate the sound pressure levels of the SR-3 propeller. Figure 6 shows the directivity of the loading noise component of the blade passing frequency (BPF) tone level for the two cases. In this figure and in the subsequent ones for directivity, the "predicted" curves are lines drawn through all the predicted points. Sound pressure levels computed with the pressure distributions obtained with the nonreflecting boundary condition show an increase in SPL ahead of the peak location and a small decrease behind it, compared to those obtained with the hard wall boundary condition. The maximum difference in the SPL occurs in the plane of the propeller and is about $2 \mathrm{~dB}$. It is also seen that a local minimum exists in the plane of the propeller in both cases.

The overall sound pressure levels (loading plus thickness) are shown in Fig 7. Also shown are the Jetstar flight test datall for comparison. The flight data were corrected for the effects of refraction in the fuselage boundary layer and scattering at the surface of the fuselage or boom based on Ref. 12 (see also Ref. 5). The trends of the two curves are nearly the same as in Fig. 6: in the nonreflecting boundary condition case the predicted SPL is higher ahead of the peak location and slightly lower behind it, compared to the hard wall boundary condition case. The maximum difference between the two cases is at the plane of the propeller and is about $1.5 \mathrm{~dB}$. It is interesting to note that although the far field hard wall boundary condition is found to result in significant overpredictions in the aerodynamic calculations, 8 it affects the predicted SPL only marginally.

The predicted sound pressure levels agree fairly well with data, with the predictions using the nonreflecting boundary condition giving a slightly better agreement. The reason for the rapid fall-off of the fuselage microphone data in the aft quadrant is not known. One point to note here is the following: although the loading obtained with the nonreflecting boundary condition is less than that with the hard wall boundary condition (Fig. 4), the SPL predicted ahead of the propeller is higher in the nonreflecting case. This is due to the differences in chordwise loading distribution between the two cases and will be discussed in more detail later in this paper.

Figure 8 shows the directivity of the second harmonic of the BPF. The predicted loading noise component and the total noise level for the two boundary conditions are shown. The trends of the two curves are similar to those observed in Figs. 6 and 7 . However, the differences between the SPL levels for the two boundary conditions are small. The agreement of the predicted total noise level with the data is good.
The spectrum of the loading component of the propeller noise is shown in Fig. 9, for the two boundary conditions. Noticeable differences in SPL levels of the two cases occur only for the first and second harmonics. Figure 10 shows the spectrum of overall noise in the plane of the propeller. Again, the boundary conditions affect the predicted SPL levels of only the first two harmonics.

Further discussions will be based on the results obtained using the blade pressure distributions obtained with the nonreflecting boundary condition.

\section{Chordwise Loading and Directivity}

Efforts to understand the directivity obtained with the pressure distribution for a nonreflecting boundary condition (Figs. 6 and 7) led to an examination of the effect of chordwise loading on directivity. The fact that accurate noise predictions for the propeller require accurate estimates of the chordwise loading distribution has been stressed by Hanson 13 and Farassat. ${ }^{7}$ Hanson observes that (1) "peaked" chordwise loading distributions should be avoided to take advantage of the chordwise noncompactness, and (2) shifting the loading to the trailing edge causes a phase 1 ag which would be used to promote phase cancellation between signals from different radij of the blade. However, the effect of these two factors on directivity is not clear.

To investigate the effects of chordwise loading distribution on the tone directivity, the loading was increased near the leading edge and decreased near the trailing edge along the entire span of the blade. Figures $11(a)$ and (b) show the modified chordwise (at 37 percent span, as typical) and spanwise loading distributions. This modified loading resulted in a 9 percent increase in blade power. The directivities obtained with these loadings are compared in Fig. 11(c) at the microphone positions of flight test. The sound pressure levels in these comparisons have been scaled to the design power. The modified loading distribution results in lower tone levels forward of the propeller plane. The directivity effect is similar to the results with the hard wall boundary condition in Figs. 6 to 8 , when a correction is applied for the difference in predicted total mechanical power levels.

\section{Acoustic Pressure Signatures and Spectra}

The computed acoustic pressure signature in the $p l a n e$ of the propeller (corresponding to the boom microphone 3) js shown in Fig. 12 along with the measured data. 14,15 The agreement of the predicted signature with data is qood.

Farassat 14,16 observes that the shape of the acoustic pressure signature depends on the chordwise loading distribution. He finds that a triangular chordwise loading with the peak at the leading edge produces a wave form 16 which is in good agreement with data.

The predicted and measured spectra corresponding to the boom microphone positions are shown in Fig. 13. The agreement of the predicted levels with the data is good for the first three harmonics. The reason for the discrepancies at higher harmonics are not known. The new formulation of 
Farassat 14,16 also shows such discrepancies. Frequency domain calculations of higher harmonics of advanced propellers have not been reported. For low speed propellers, frequency domain calculations of Williams 17 and time domain calculations of Farassat ${ }^{18}$ show good agreement with the data up to six harmonics.

\section{Directivities of the BPF Harmonics}

Here we examine the directivities of the harmonics of the BPF and also those of the individual loading and thickness components of the harmonics. Figure 14(a) shows the thickness, loading, and total noise directivities of the blade passing frequency tone level. The thickness noise shows a maximum just aft of the plane of rotation of the propeller. The loading noise component shows a local minimum in the plane of the propeller. The directivity of the total noise shows that the maximum noise level occurs aft of the propeller at about 0.25 meters from the plane of rotation, which coincides with the location indicated by the flight data. The frequency domain calculations of the directivity of the total noise reported in Refs. 12 and 15 also show the maximum to occur aft of the plane of rotation of the propeller, but indicate a local minimum to occur in the plane of rotation. These calculations employ the near field frequency domain theory of Hanson. 19 The total noise directivity calculations reported in Ref. 20, which uses the far field frequency domain theory of Hanson 13,21 does not show a local minimum in the plane of the propeller. The differences between the calculations of the time domain and frequency domain 12,15 approaches could be due to the differences in input loading distributions.

Figure 14(b) shows the directivities of the second harmonics and its components. The total noise directivity shows a fairly good agreement with data. Similar agreement of the total noise directivity with the data is also observed for the third harmonics (Fig. 14(c)). The predicted total noise of the fourth and fifth harmonics (Figs. 14(d) and (e)) are significantly different from the data. For these and higher harmonics the present numerical method appears inadequate. Figure 15 shows the directivities of the total noise of the first five harmonics of the BPF for comparison. As the harmonic number increases, the SPL at all angles tends to decrease. Amplitude irreqularities around the $\mathrm{plane}$ of rotation at the fourth and fifth harmonics may be artifacts of the numerics. Detailed experimental directivities are unavailable.

\section{Conclusions}

The acoustic significance of the far field boundary conditions (hard wall and nonreflecting) employed in aerodynamic calculations has been studied. The present computations show that the maximum difference in the computed SPL due to the use of a hard wall boundary condition, in place of a nonreflecting boundary condition, is about 1.5 $d B$. While the acoustic difference is small, the nonreflecting boundary condition is clearly more correct physically, and has been shown to give superior aerodynamic results. The location and level of the maximum of the BPF tone level predicted by the present calculations are in agreement with flight data. The chordwise loading distribu- tion influences the relative levels of the SPL fore and aft of the propeller. It appears that the prediction of harmonics higher than the third needs refined approaches.

\section{References}

1. Mikkelson, D.C., Mitchell, G.R., and Bober, L.J., "Summary of Recent NASA Propeller Research," Aerodynamics and Acoustics of Propellers, AGARD CP-366, AGARD, France, 1984, pp., 12.1-122.21.

2. Metzger, F.B., "Progress and Trends in Propeller/Propf an Noise Technology," AIAA Paper 80-0856, May 1980.

3. Propeller Performance and Noise, VKI-LS-1982-08-vol-1; -vol-2, Von Karman Institute for Fluid Dynamics, Belgium, 1982.

4. Aerodynamics and Acoustics of Propellers, AGARD CP-366, AGARD, France, 1985.

5. Clark, B.J. and Scott, J., "Coupled Aerodynamic and Acoustical Predictions for Turboprops," NASA TM-87094, 1986.

6. Denton, J.D., "Time Marching Methods for Turbomachinery Flow Calculations," Numerical Methods in Fluid Dynamics, ed. B. Hunt, Academic Press, New York, 1980 , pp. 473-493.

7. Nystrom, P.A. and Farassat, F., "A Numerical Technique for Calculation of the Noise of High-Speed Propeller with Advanced Blade Geometry," NASA TP-1662, 1980.

8. Nall asamy, M., Clark, B.J., and Groeneweg, J.F., "Euler Analysis of the Three-Dimensional Flow Field of a High Speed Propeller: Boundary Condition Effects, "to be presented at the 32nd ASME International Gas Turbine Conference, 1987.

9. Hanson, D.B., "Compressible Lifting Surface Theory for Propeller Performance Calculations," Journal of Aircraft, Vol. 22, No. 1, Jan. 1985, pp. 19-27.

10. Martin, R.M. and Farassat, F., "User's Manual for a Computer Program to Calculate Discrete Frequency Noise of Conventional and Advanced Propellers," NASA TM-83135, 1981.

11. Brooks, B.M., "Analysis of Jetstar Propfan Acoustic Flight Test Data," Hamilton Standard, HSER-8882, 1983.

12. Hanson, D.B. and Magliozzi, B., "Propagation of Propeller Tone Noise Through a Fuselage Boundary Layer," Journal of Aircraft, Vol. 21, No. 1 , Jan. 1985, pp. 63-70.

13. Hanson, D.B., "Influence of Propeller Design Parameters on Far Field Harmonic Noise in Forward Flight," AIAA Journal, Vol. 18, No. 11 , Nov. $1980, \mathrm{pp}$. 1313-1319.

14. Farassat, F., Dunn, M.H., and Padula, S.S., "Advanced Turboprop Noise Prediction Development of a Code at NASA Langley Based on Recent Theoretical Results," NASA TM-88993, 1986. (AIAA Paper 84-2303) 
15. Brook, B.M. and Macka11, K.G., "Measurement and Analys is of Acoustic Flight Test Data for Two Advanced Design High Speed Propeller Models," AIAA Paper 84-0250, Jan. 1984.

16. Farassat, F., "Prediction of Advanced Propeller Noise in the Time Domain," AIAA Journal, Vol. 24, No. 4, Apr. 1986, pp. 578-584.

17. Williams, J., "Propeller Noise Prediction and Research Techniques, " Propeller Performance and Noise, Vol. 1, VKI-LS-1982-08-VoT-1, Von Karman Institute for Fluid Dynamics, Belgium, 1982.

18. Farassat, F., "Advanced Theoretical Treatment of Propeller Noise," Propeller Performance and Noise, Vol. 1, VKI-LS-1982-08-Vol-1, Von Karman Institute for Fluid Dynamics, Belgium, 1982.
19. Hanson, D.B., "Near-Field Frequency Domain Theory for Propeller Noise," AIAA Journal, Vol. 23 , No. 4, Apr. 1985, pp. 499-504.

20. Brooks, B.M, "Acoustic Measurements of Three Propfan Models," AIAA Paper 80-0995, June 1980.

21. Hanson, D.B., "Helicoidal Surface Theory for Harmonic Noise of Propellers in the Far Field," AIAA Journal, Vol. 18, No. 10, Oct. 1980 , pp. 1213-1220. 


\section{ORIGINAL PAGE IS OF POOR QUALTTY}

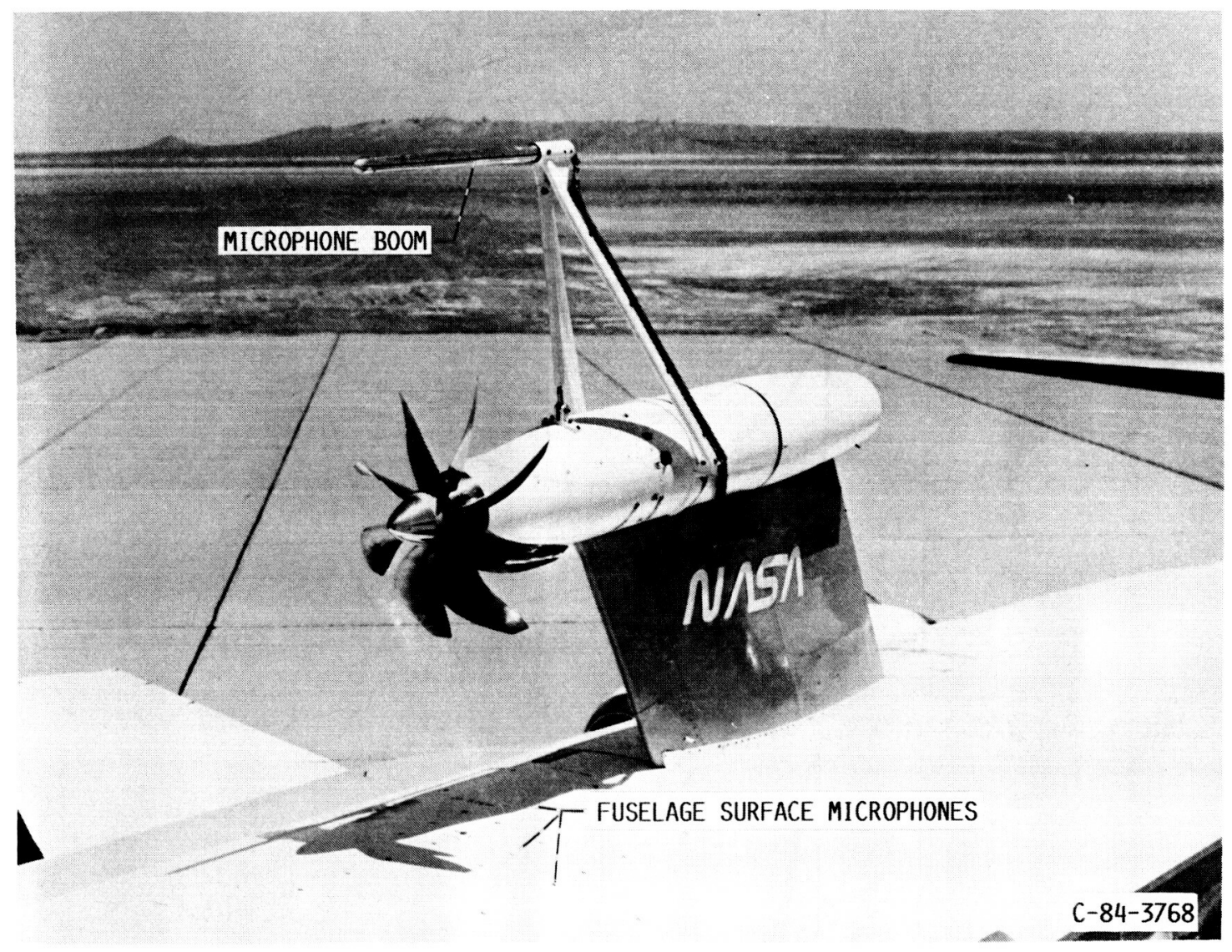

FIGURE 1.- SR-3 PROPELLER INSTALLED ON JETSTAR AIRCRAFT FOR FLIGHT TEST. 

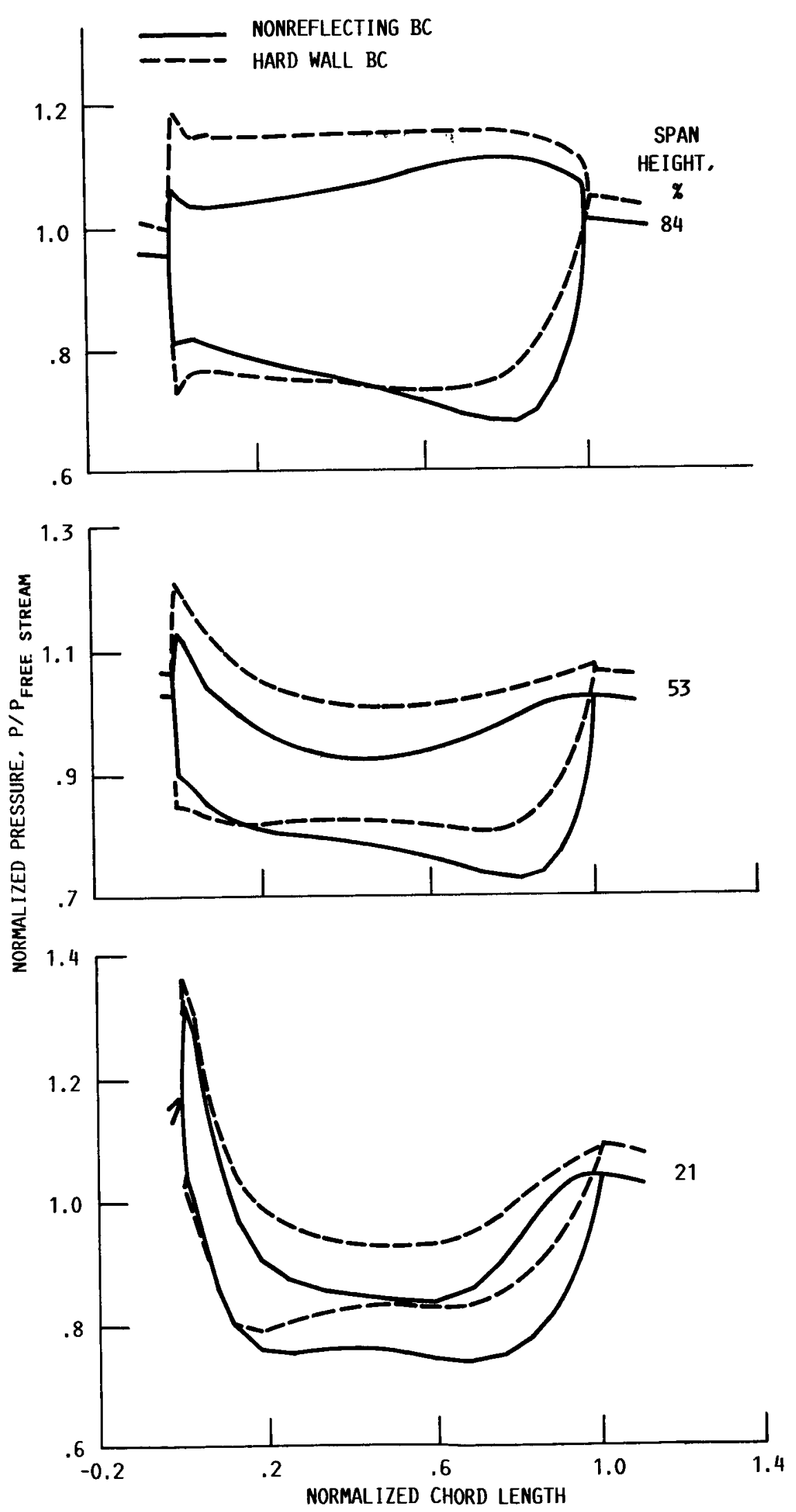

FIGURE 2. - BLADE PRESSURE DISTRIBUTION. 


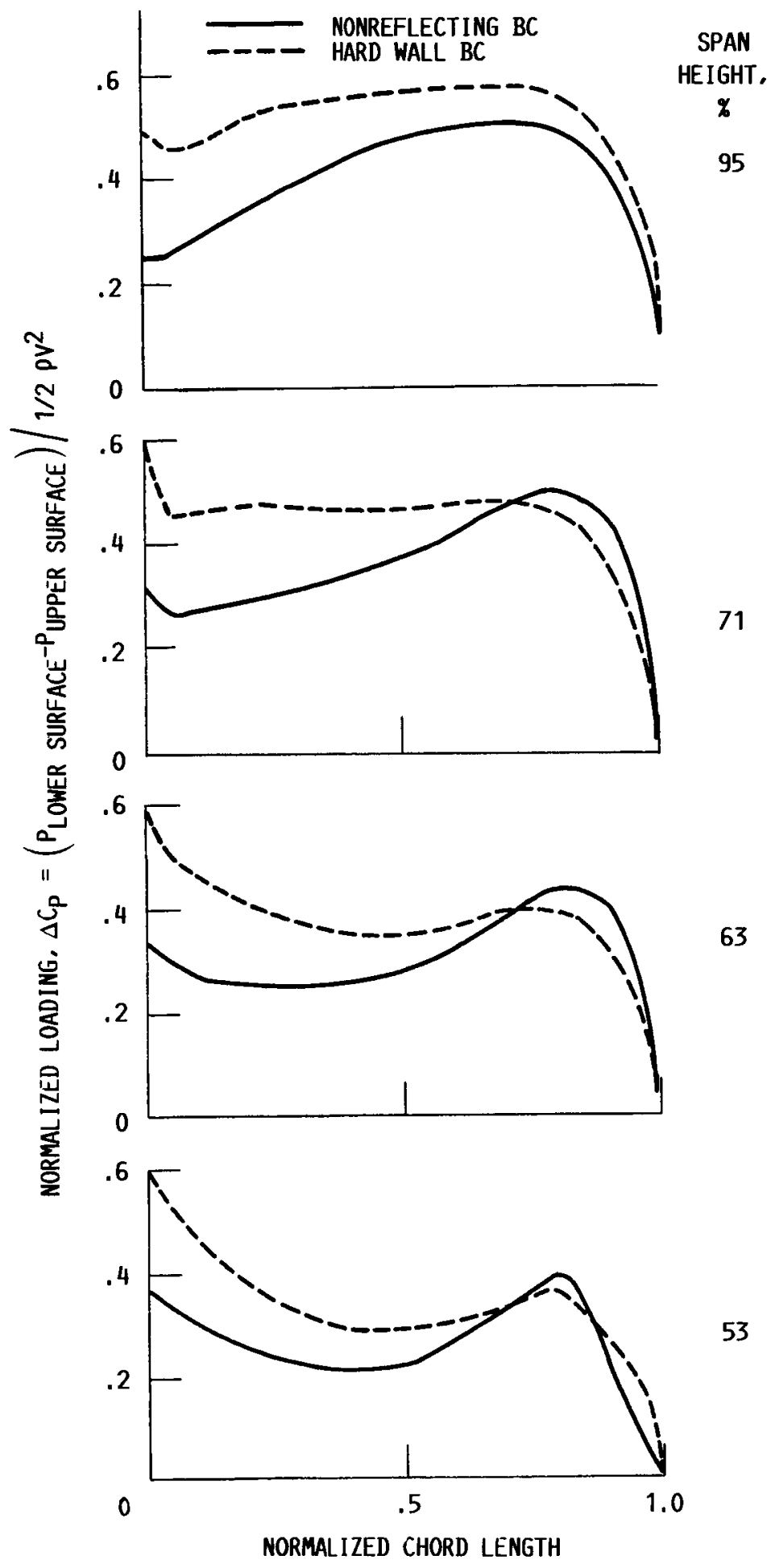

FIGURE 3.- CHORDWISE LOADING DISTRIBUTION. 


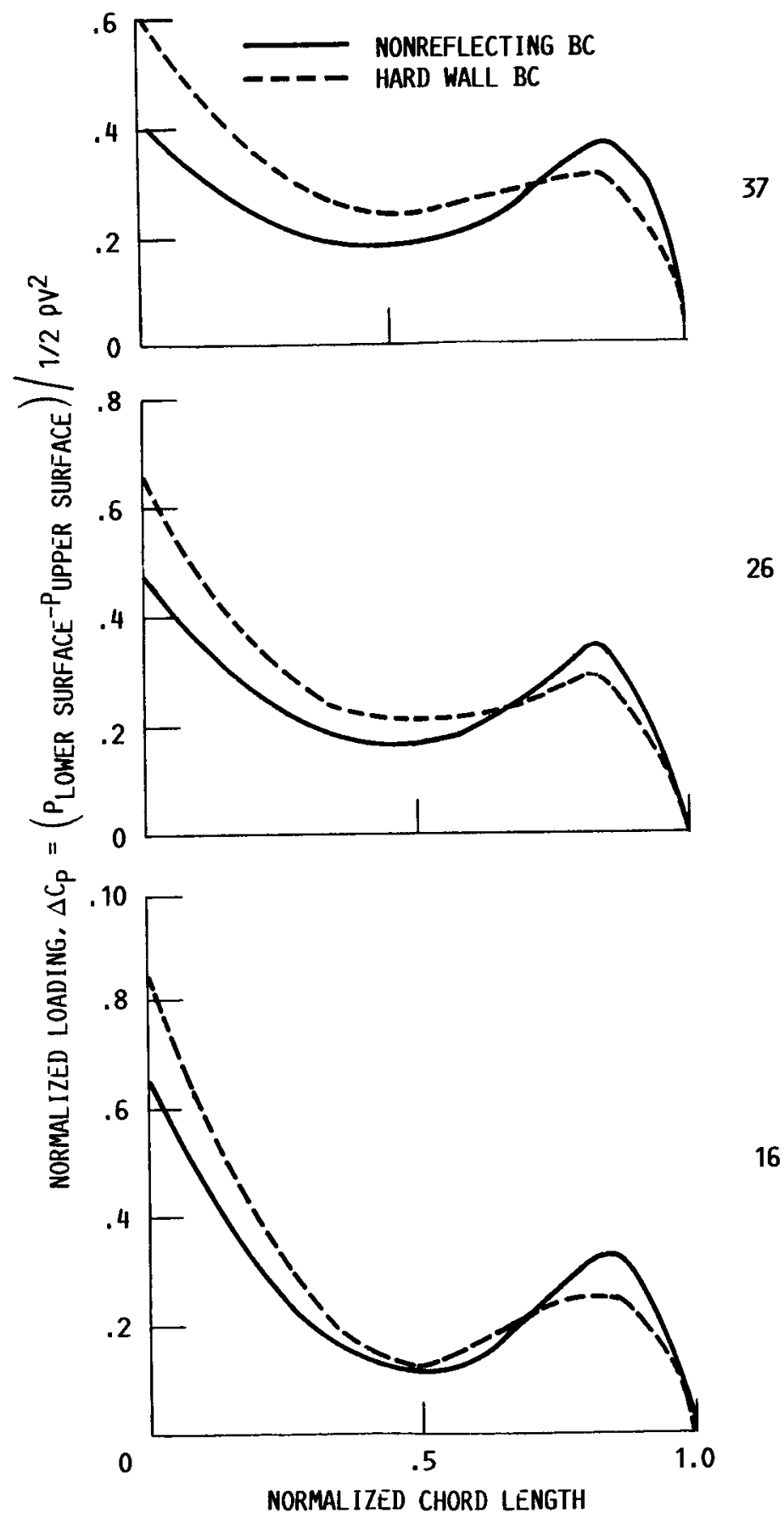

FIGURE 3. - CONCLUDED. 


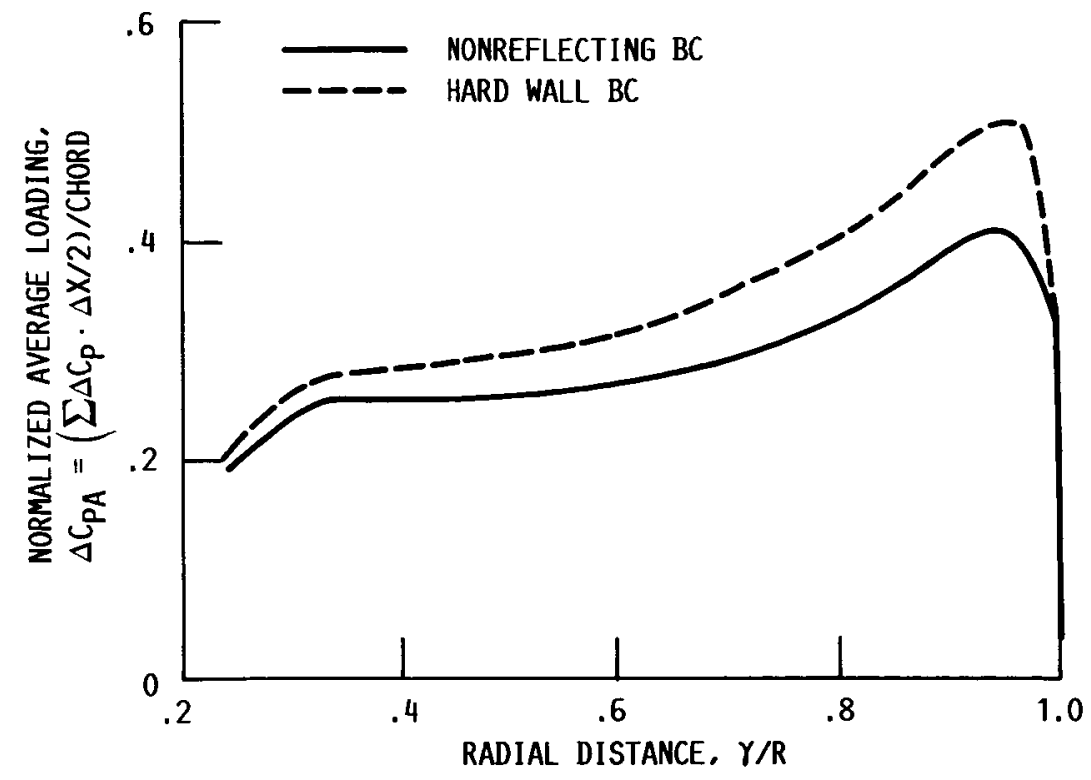

FIGURE 4.- SPANWISE LOADING DISTRIBUTION.

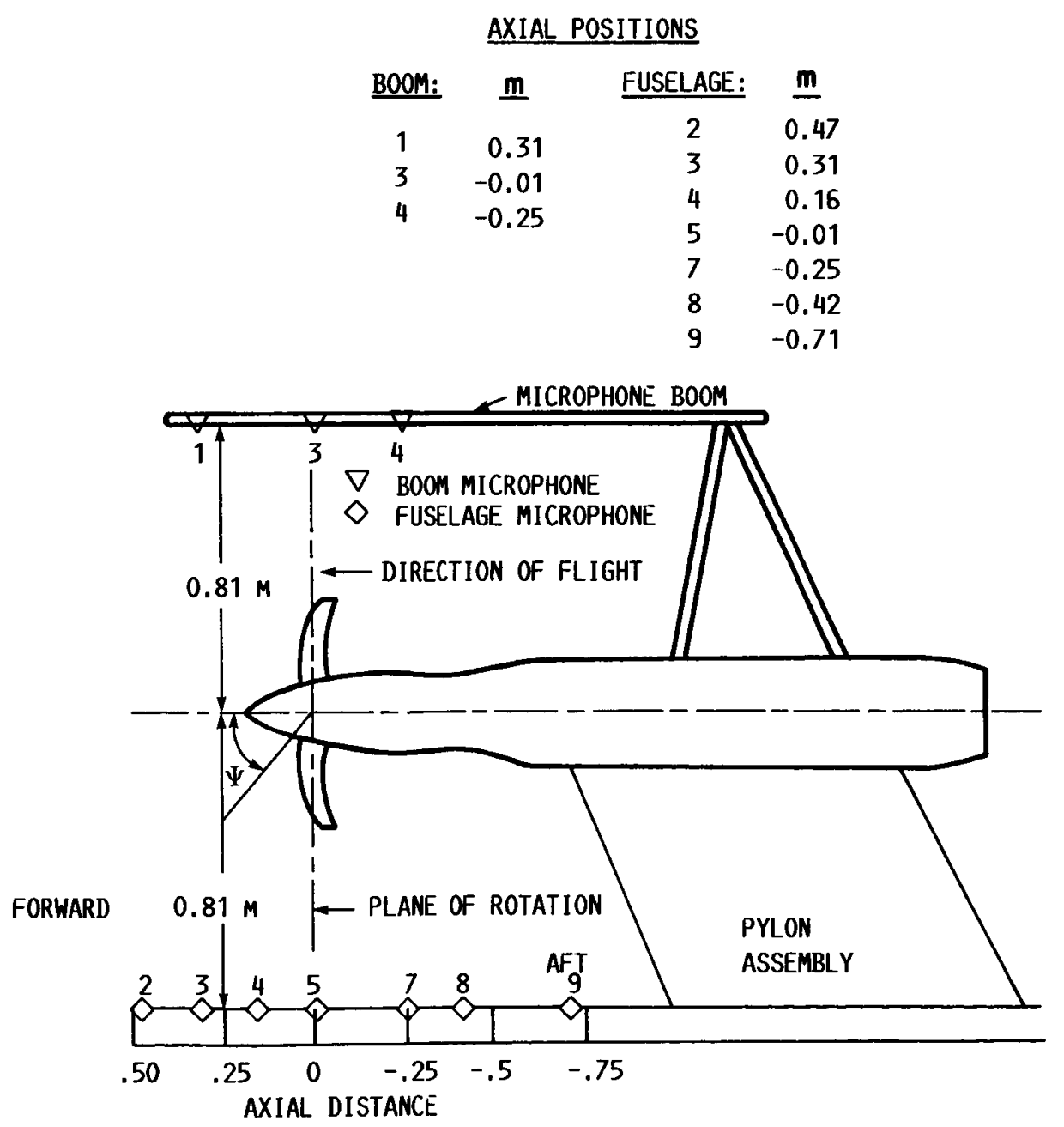

FIGURE 5. - MICROPHONE POSITIONS IN JETSTAR FLIGHT TEST. 


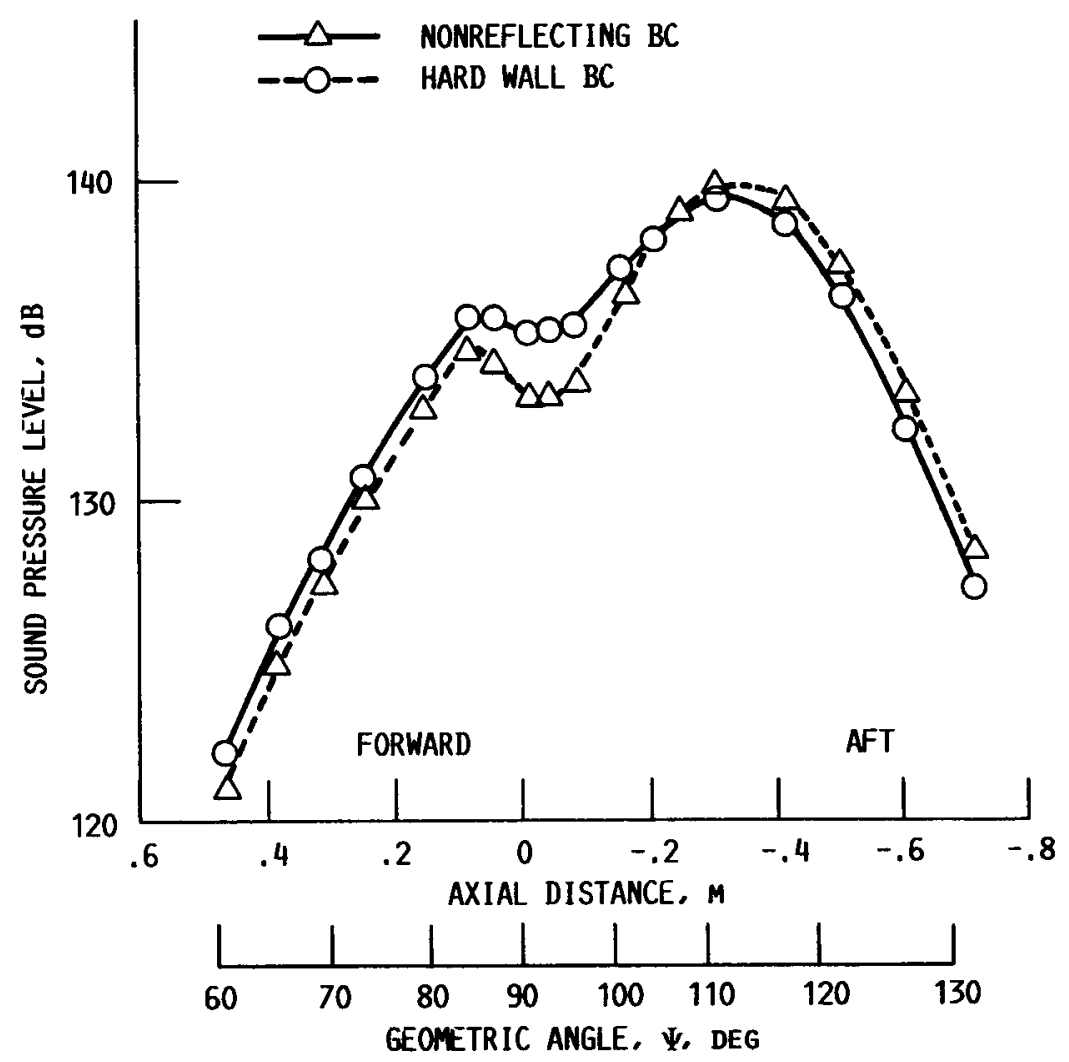

FIGURE 6. - CALCULATED DIRECTIVITIES OF LOADING NOISE COMPONENT OF BPF. 


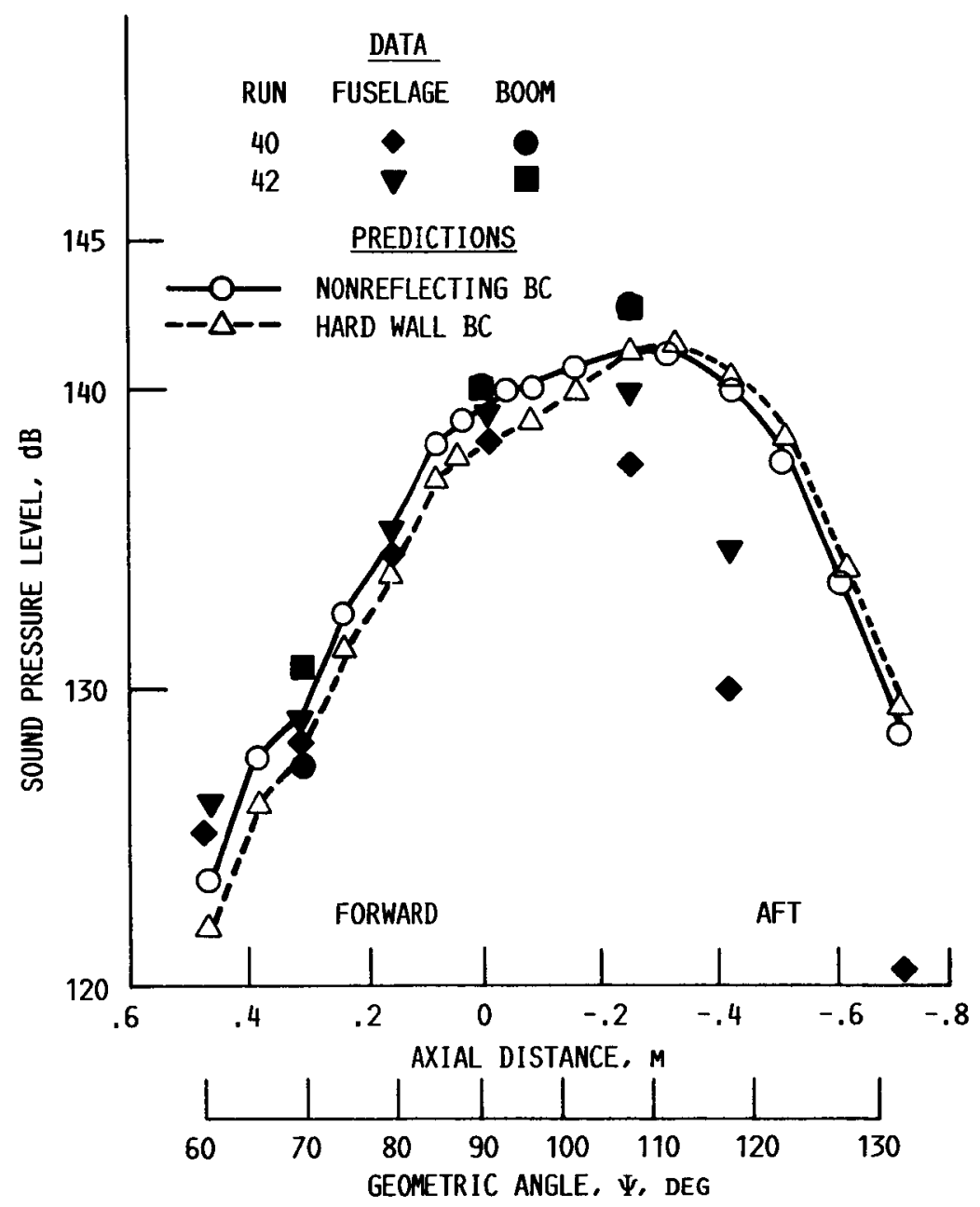

FIGURE 7.- DIRECTIVITY OT TOTAL NOISE AT BPF (DESIGN7348.5 RPM: RUN $40=7314$ RPM: RUN $42=7569$ RPM). 


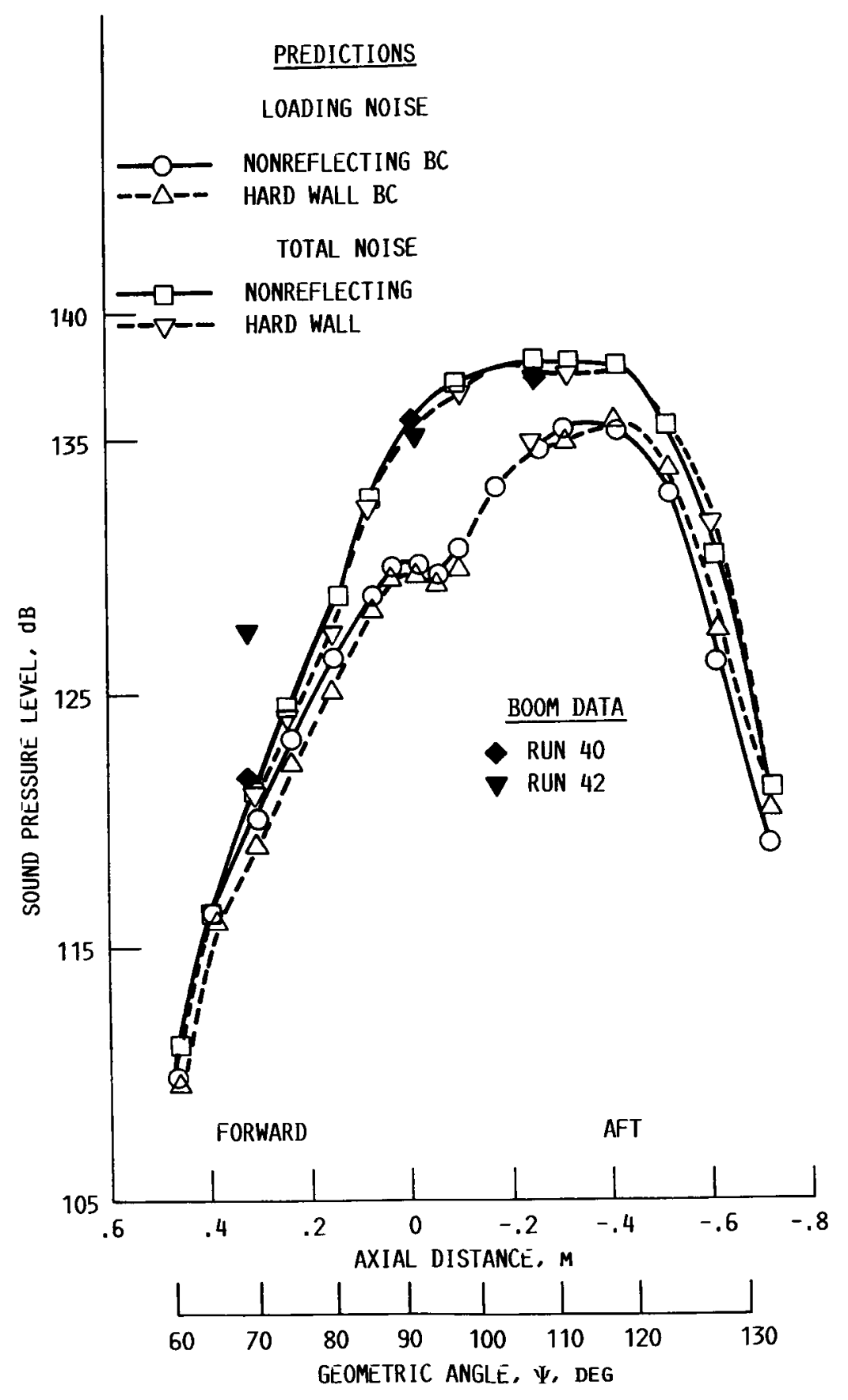

FIGURE 8. - DIRECTIVITY OF $2 \times$ BPF. 


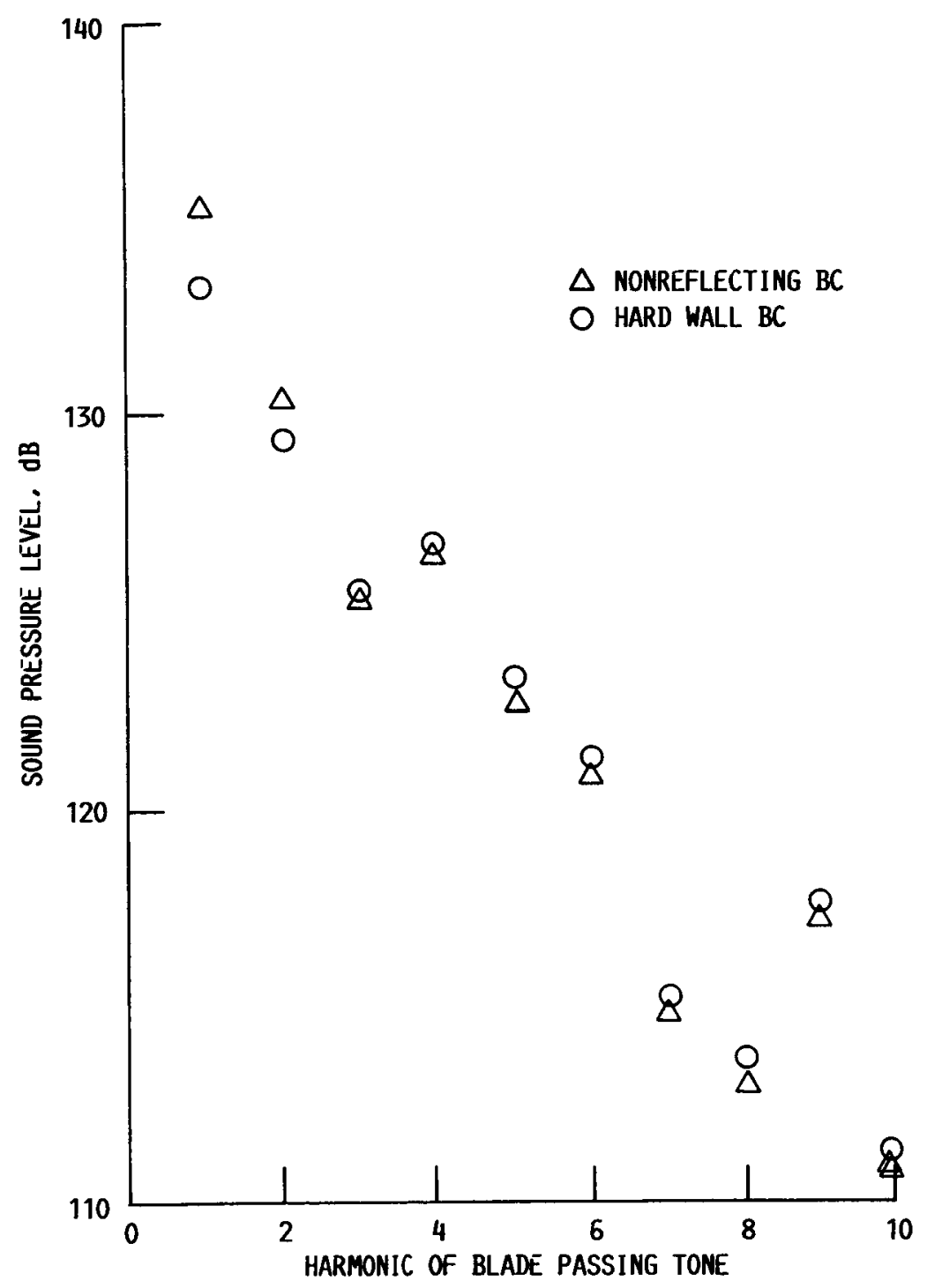

FIGURE 9. - CALCULATED LOADING SPECTRA AT $0.81 \mathrm{M}$ SIDELINE IN PROPELLER PLANE. 


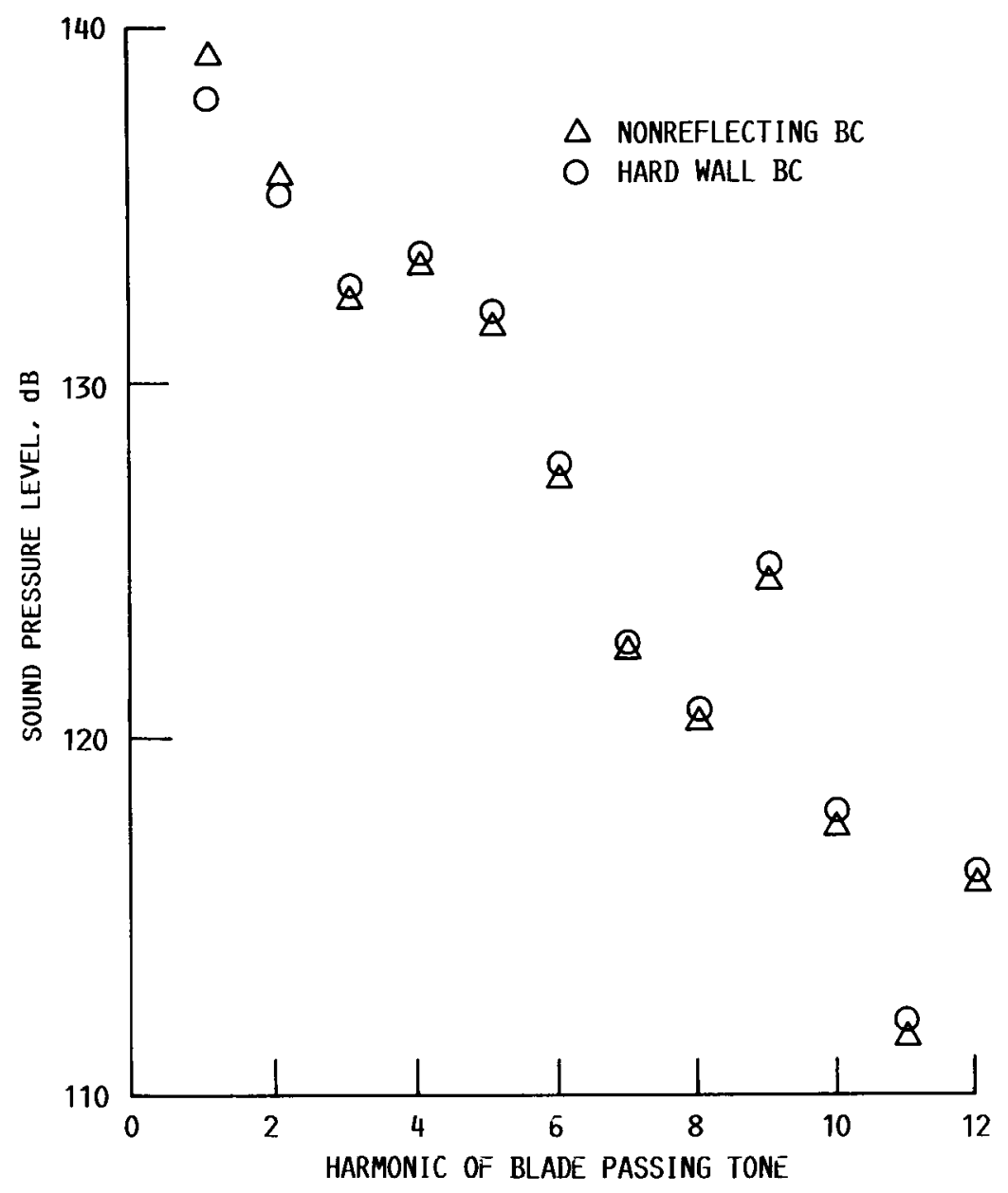

FIGURE 10. COMPUTED TOTAL SPECTRA AT $0.81 \mathrm{M}$ SIDELINE TO PROPELLER PLANE. 

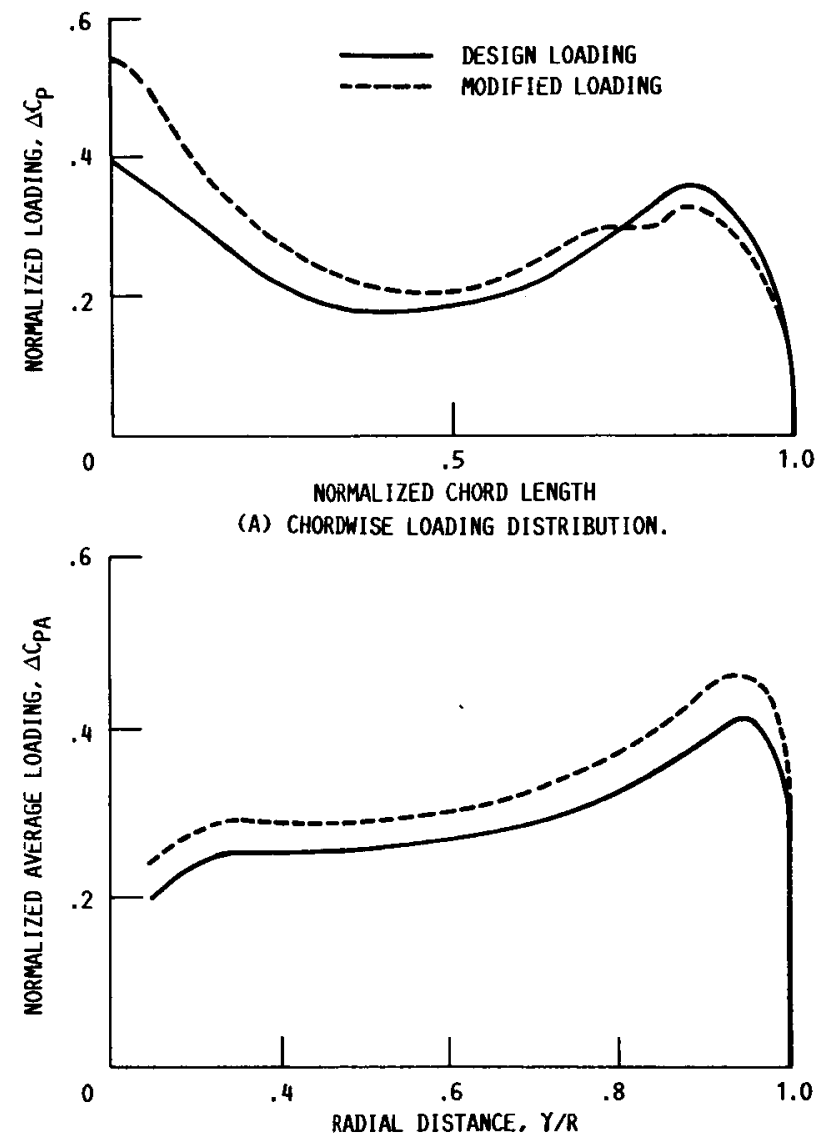

(B) RADIAL LOADING DISTRIBUTION.

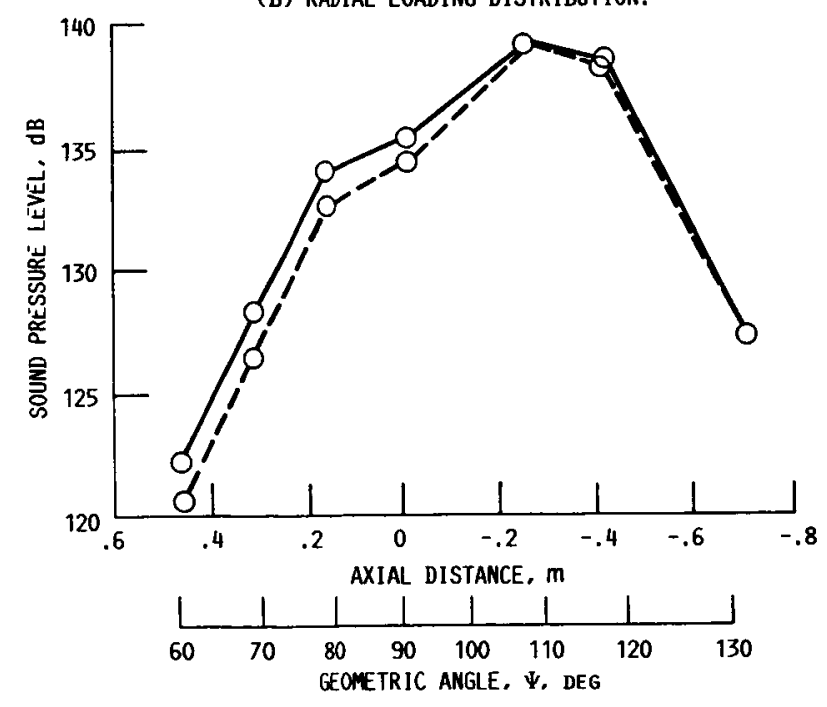

(C) BPF TONE DIRECTIVITY.

FIGURE 11. - EFFECT OF CHORDWISE LOADING ON BPF DIRECTIVITY. 


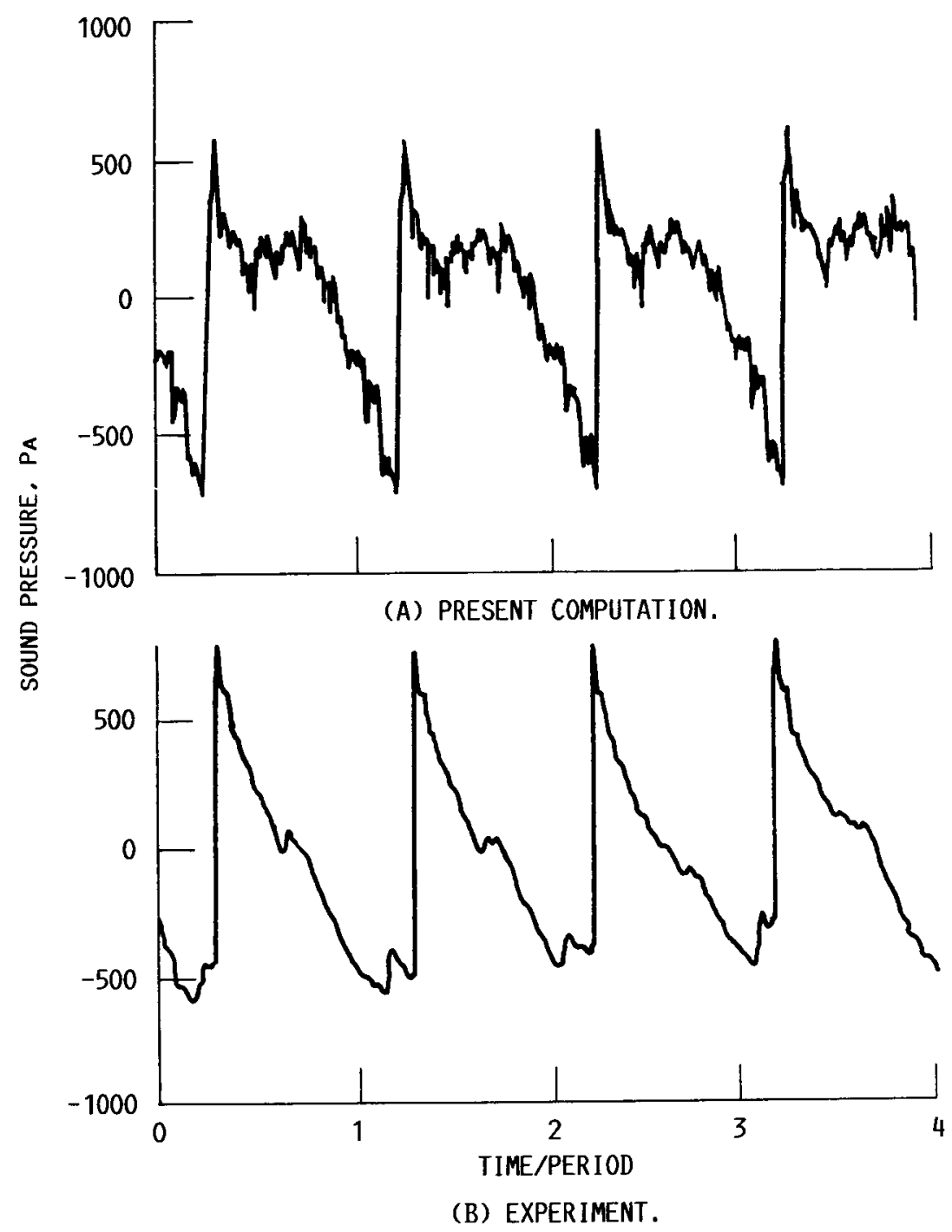

FIGURE 12.- WAVEFORMS IN THE PLANE OF THE PROPELLER (BOOM MICROPHONE 3). 


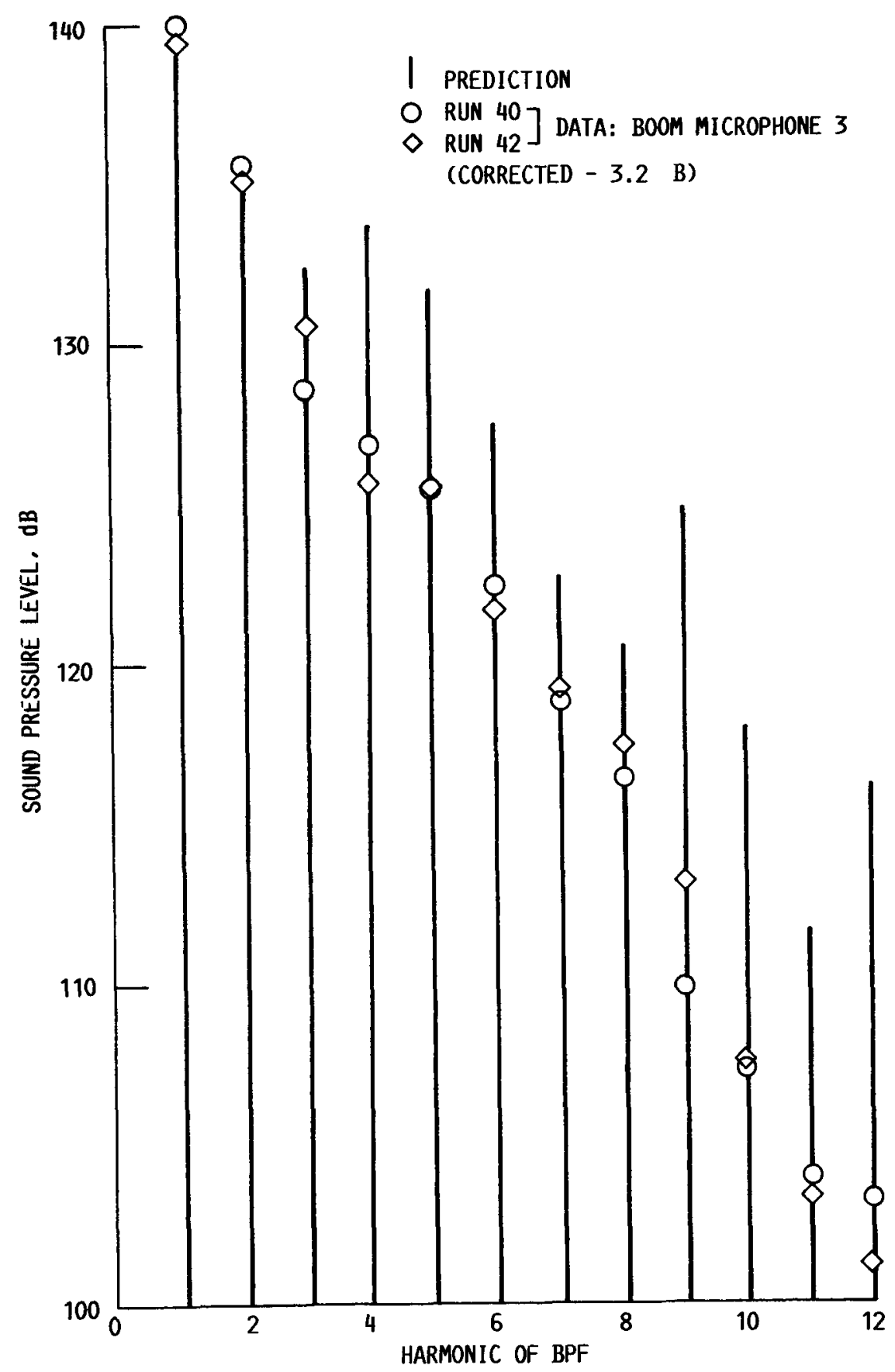

(A) NOISE SPECTRUM IN THE PLANE OF THE PROPELLER: BOOM MICROPHONE 3.

FIGURE 13.- NOISE SPECTRA. 


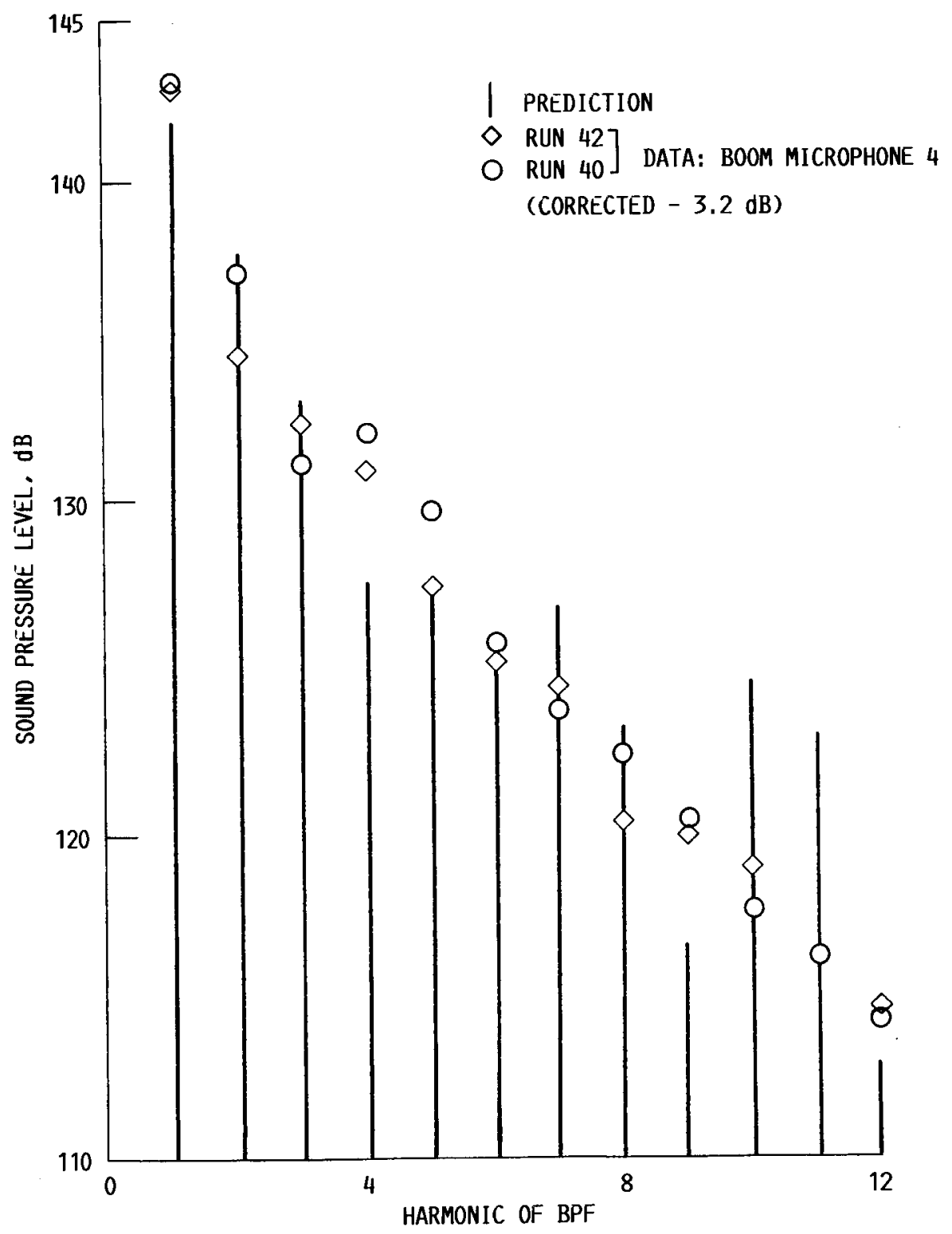

(B) NOISE SPECTRUM: BOOM MICROPHONE 4.

FIGURE 13.- CONTINUED. 
Original page is

OF POOR CIIALITY

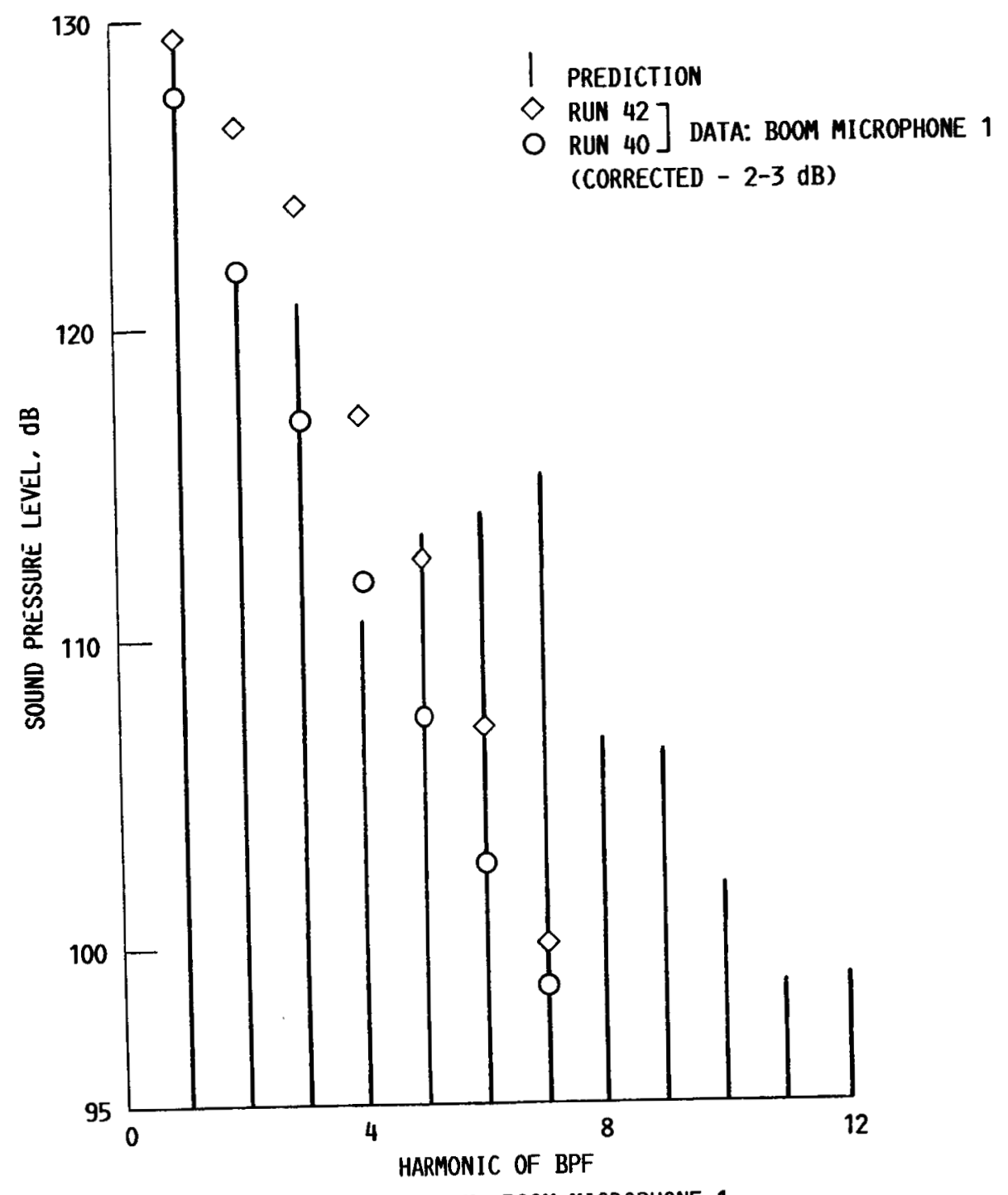

(C) NOISE SPECTRUM: BOOM MICROPHONE 1.

FIGURE 13.- CONCLUDED. 


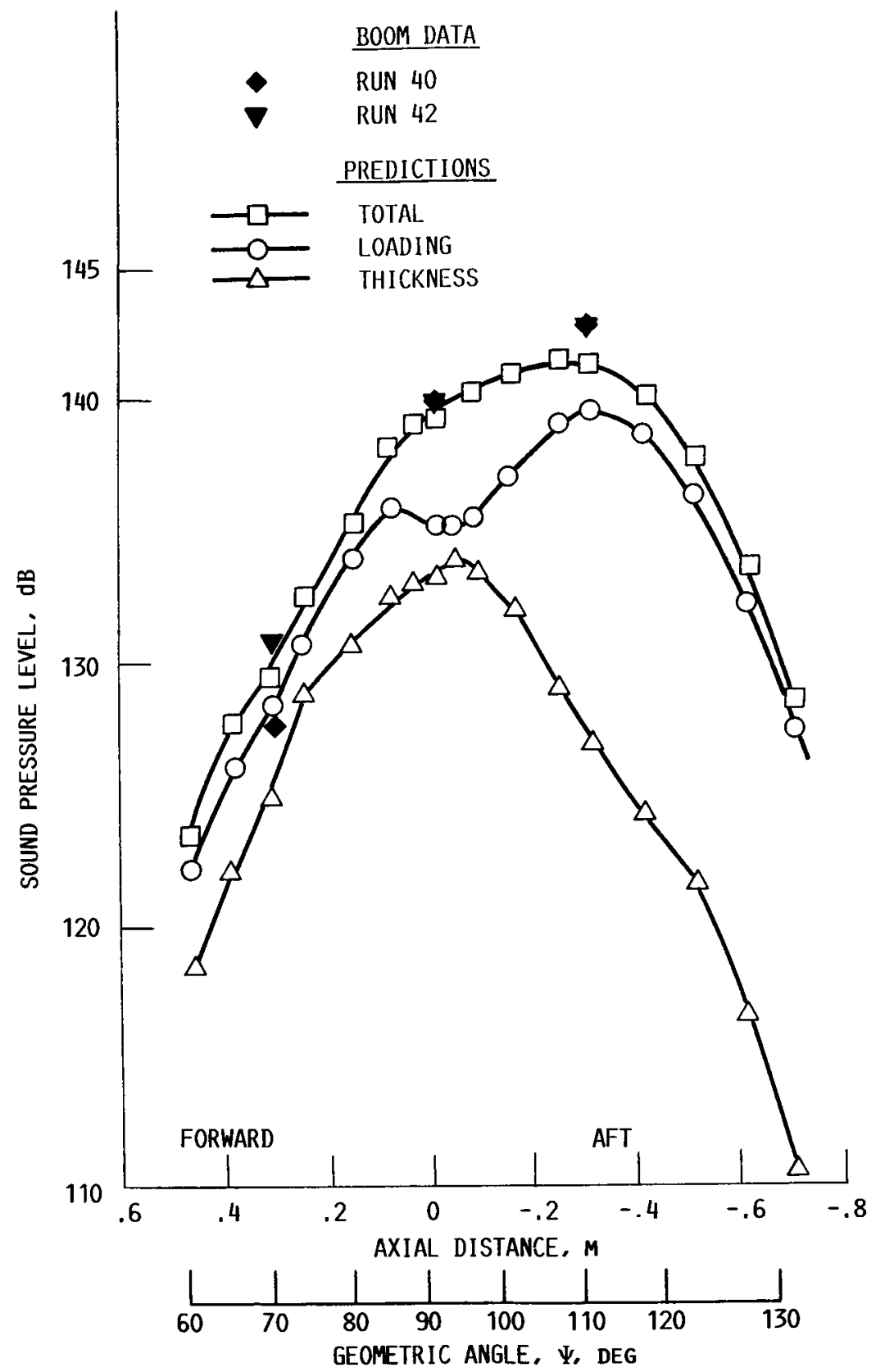

(A) DIRECTIVITIES OF BPF.

FIGURE 14. - DIRECTIVITIES OF BPF AND ITS HARMONICS. 


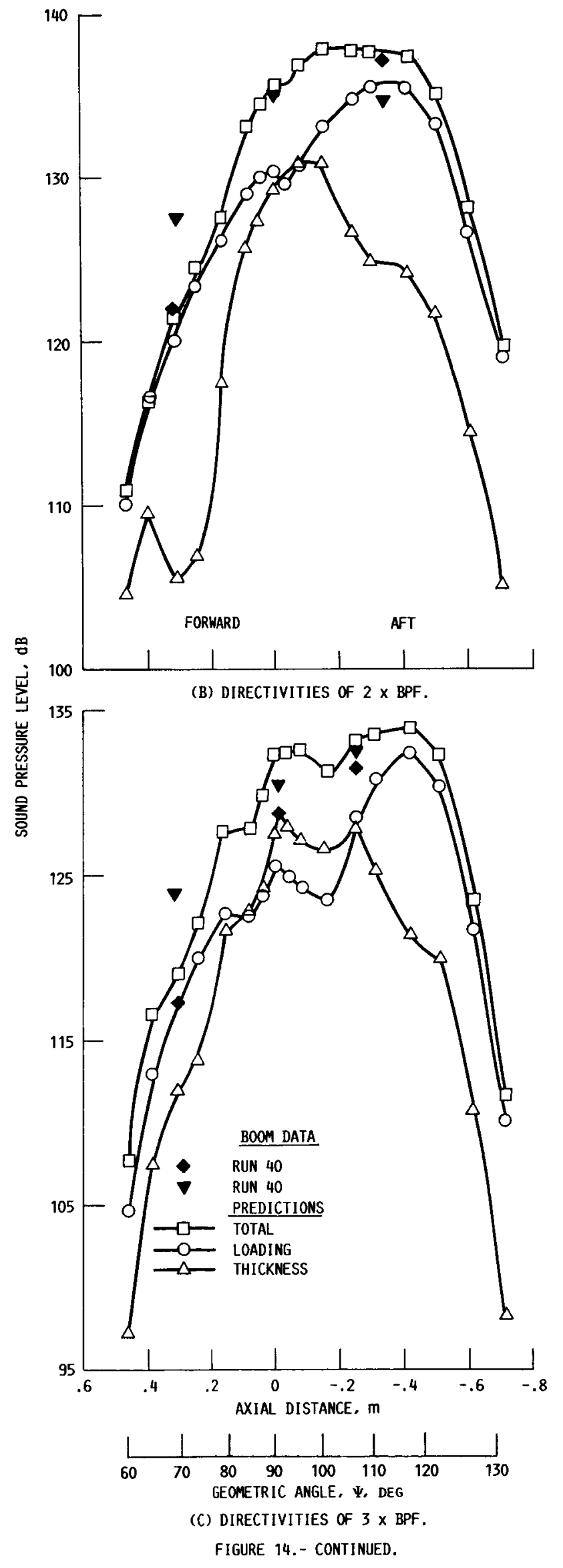




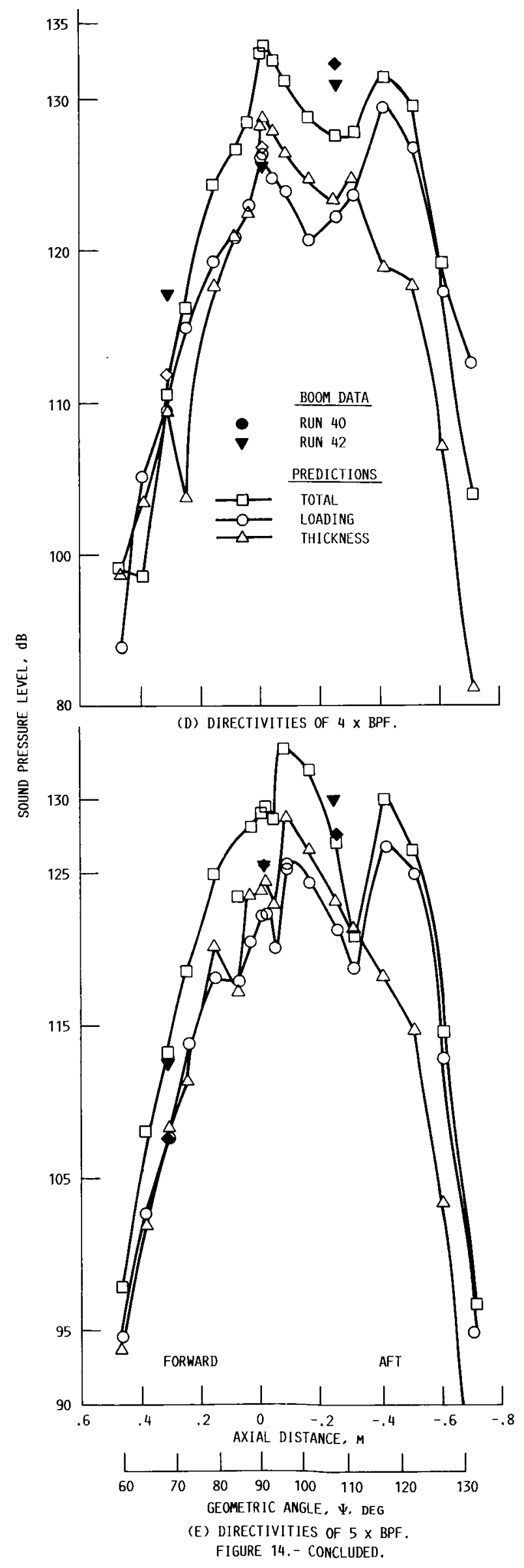




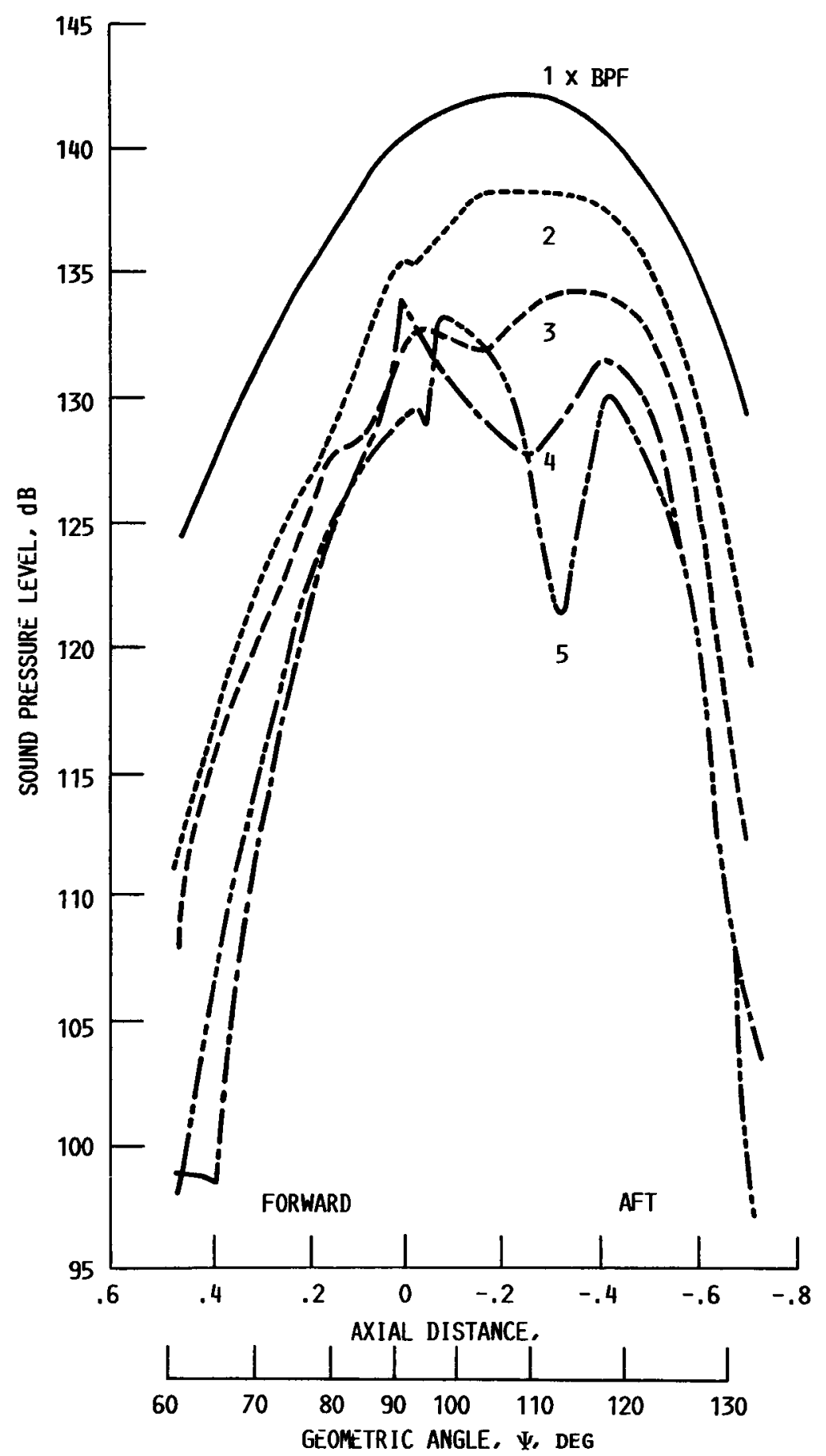

FIGURE 15. - CALCULATED DIRECTIVITIES OF THE FIRST FIVE HARMONICS. 


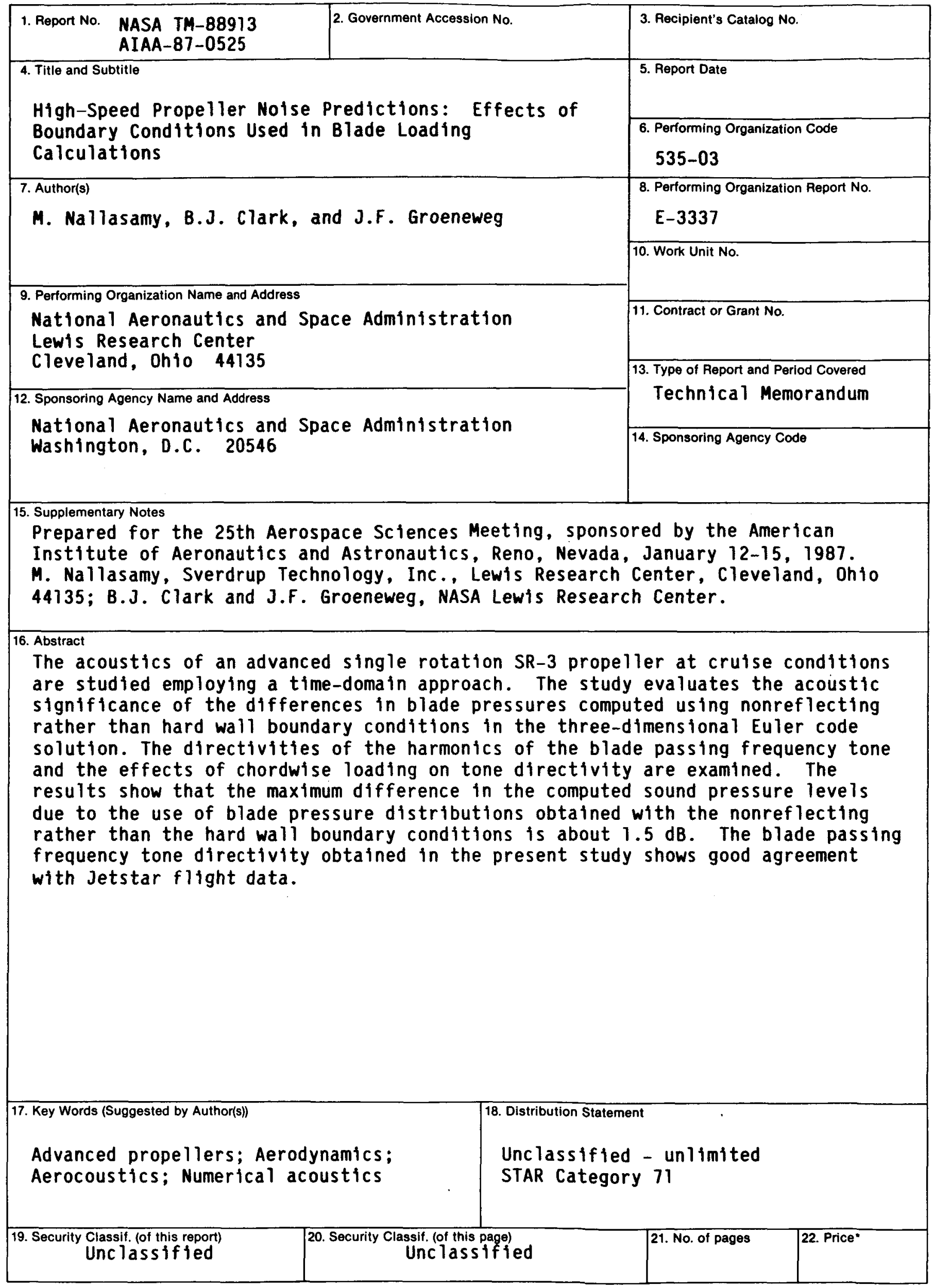

"For sale by the National Technical Information Service, Springfield, Virginia 22161 